\title{
Mycobacterium tuberculosis and the host cell inflammasome: a complex relationship
}

\author{
Volker Briken *, Sarah E. Ahlbrand and Swati Shah
}

Department of Cell Biology and Molecular Genetics, University of Maryland, College Park, MD, USA

\section{Edited by:}

Jean-Pierre Gorvel, Centre National de la Recherch Scientifique, France

Reviewed by:

Thomas Henry, Institut National de la Santé et de la Recherch Médicale, France

Olivier Neyrolles, Centre National de la Recherche Scientifique, France

\section{*Correspondence}

Volker Briken, Department of Cell Biology and Molecular Genetics,

University of Maryland,

Microbiology Bldg. \#231, room

2201, College Park, MD 20742, USA

e-mail:vbriken@umd.edu
The production of $\mathrm{IL}-1 \beta$ during the infection with Mycobacterium tuberculosis (Mtb) is important for successful host immune defense. In macrophages and dendritic cells the host cell inflammasome is crucial for generation of secreted IL-1 $\beta$ in response to Mtb infections. In these cell types Mtb infection only activates the NLRP3-inflammasome. New reports demonstrate that nitric oxide has an important function in the negative regulation of the NLRP3-inflammasome to reduce tissue damage during Mtb infections. The type I interferon, IFN- $\beta$, is induced after Mtb infections and can also suppress NLRP3-inflammasome activation. In contrast, IFN- $\beta$ increases activity of the AIM2-inflammasome after infection with intracellular pathogens such as Francisella tularensis and Listeria monocytogenes. Recent results demonstrate that non-tuberculous mycobacteria but not virulent Mtb induce the AIM2-inflammasome in an IFN- $\beta$ dependent matter. Indeed, Mtb inhibits AIM2-inflammasome activation via its ESX-1 secretion system. This novel immune evasion mechanism may help Mtb to allow the induction of low levels of IFN- $\beta$ to suppress the NLRP3-inflammasome without activating the AIM2-inflammasome.

Keywords: Mycobacterium tuberculosis, ESX-1, IFN- $\beta$, inflammasome, IL-1 $\beta$, NLRP3, AIM2

\section{INTRODUCTION}

IL-1 $\beta$ is important for host immune defense against Mtb, since several studies demonstrated that IL-1 $\beta$ and IL-1-receptor knockout mice are more susceptible to Mtb infections (Mayer-Barber et al., 2010, 2011; Mcelvania Tekippe et al., 2010). According to some studies IL-18 has no or only a minor role in host defense against Mtb but more recently one report showed an increased susceptibility of IL-18 but not IL-18R knockout mice [for review (Cooper et al., 2011)]. In macrophages and dendritic cells the production of mature IL- $1 \beta$ and IL-18 is dependent on activation of the inflammasome (Schroder and Tschopp, 2010). Within the inflammasome complex, the cleavage of pro-IL- $1 \beta$ and pro-IL-18 is mostly performed by caspase- 1 with help of caspase11 (Rathinam et al., 2012). Nevertheless, there is a fraction of cytokine maturation that is not performed by the caspase-1/11 pathway (Mayer-Barber et al., 2010; Mcelvania Tekippe et al., 2010; Abdalla et al., 2012) but most likely by caspase-8 (Gringhuis et al., 2012). The NLR (nucleotide-binding and oligomerization domain, leucine-rich-repeat-containing) proteins such as NLRP3 and NLRC4 are one family of cytosolic receptors, which upon ligand binding mediate inflammasome activation. In the case of $\mathrm{Mtb}$, most studies using ex vivo analysis of macrophages and dendritic cells identify NLRP3 as the sole NLR capable of inducing inflammasome activation (Carlsson et al., 2010; Mayer-Barber et al., 2010; Mcelvania Tekippe et al., 2010; Mishra et al., 2010; Wong and Jacobs, 2011; Abdalla et al., 2012; Dorhoi et al., 2012). Absent in Melanoma 2 (AIM2) is the best studied member of the HIN-200 family of DNA binding proteins, which is involved in the surveillance of the cytosol for double-stranded DNA (dsDNA)
(Burckstummer et al., 2009; Fernandes-Alnemri et al., 2009; Hornung et al., 2009). Despite an apparent failure of Mtb to activate the AIM2-inflammasome ex vivo, Aim2 ${ }^{-/-}$mice are more susceptible to Mtb infections demonstrating a role for the AIM2 inflammasome in vivo and/or a putative inflammasomeindependent function of AIM2 in host defense (Saiga et al., 2012). Here we will review and discuss the recent literature on the molecular mechanisms of the interaction of Mtb with NLRP3 and AIM2 inflammasomes and their connection with type I IFN signaling.

\section{INTERACTION OF MTB WITH HOST CELL NLRP3-INFLAMMASOME}

Infection of macrophages or dendritic cells deficient in NLRP3 with Mtb does not induce secretion of IL-1 $\beta$ or IL-18 (Carlsson et al., 2010; Mayer-Barber et al., 2010; Mcelvania Tekippe et al., 2010; Mishra et al., 2010; Wong and Jacobs, 2011; Abdalla et al., 2012; Dorhoi et al., 2012). The dogma for NLRs has been that they bind to a pathogen and/or danger associated molecular pattern (P/DAMP) in the host cell cytosol, which triggers their activation and subsequent formation of active inflammasomes. Nevertheless, the nature of such a ligand for NLRP3 has remained elusive. Recent publications suggest that there may not be a P/DAMP directly binding to NLRP3. Instead, cytosolic viral and bacterial RNA is sensed by DHX33, which then binds to and activates NLRP3 (Mitoma et al., 2013). Bacterial toxins, phagocytosis and other cellular insults result in potassium depletion in the cytosol, which serves as an activator of NLRP3 (Munoz-Planillo et al., 2013). Consistently, it was shown that potassium depletion 
is required for Mtb and non-tuberculous mycobacteria (NTM)mediated inflammasome activation in macrophages (Kurenuma et al., 2009; Chen et al., 2012; Dorhoi et al., 2012; Lee et al., 2012, 2013). The protein tyrosine kinase Syk has been implicated in Mtb-mediated inflammasome activation (Wong and Jacobs, 2011), which is consistent with its previously identified role in activating the NLRP3-inflammasome after infection with the fungal pathogen Candida albicans (Gross et al., 2009). Another positive regulator is the thioredoxin-interacting protein that is activated by the loss of binding to thioredoxin after increase in cytosolic reactive oxygen species (ROS) and which subsequently binds to NLRP3 to activate it (Zhou et al., 2010). Nevertheless, this pathway is unlikely to be involved in Mtbmediated NLRP3-inflammasome activation because inhibitors of ROS had no effect (Wong and Jacobs, 2011; Dorhoi et al., 2012). ROS-dependent and -independent pathways seem to converge at the mitochondrial membrane where the generation of the lipid cardiolipin can stimulate the NLRP3-inflammasome by binding to NLRP3 (Iyer et al., 2013). Finally, the guanylate binding protein 5 promotes NLRP3-inflammasome assembly and activation in response to bacterial infections as shown for Listeria monocytogenes and Salmonella typhimurium (Shenoy et al., 2012) but its role during Mtb infection has not been analyzed.

During the course of Mtb infections, the increase of IFN$\gamma$ in the lungs results in higher levels of nitric oxide (NO). Interestingly, NO has the capacity to negatively regulate the NLRP3-inflammasome and hence reduce IL-1 $\beta$ production (Mishra et al., 2013). The direct S-nitrosylation of NLRP3 accounts for the inhibitory effect of NO (Hernandez-Cuellar et al., 2012; Mishra et al., 2013). This aspect of NO activity is important to suppress tissue damage produced by continuous activation of innate immunity (Hernandez-Cuellar et al., 2012; Mishra et al., 2013). Another negative regulator of the NLRP3-inflammasome are omega-3 fatty acids which may prevent excessive inflammation and metabolic disorder (Yan et al., 2013). Furthermore, the LRRFIP2 binds to NLRP3 and also interacts with Flightless- 1 to stimulate its binding to and subsequent inhibition of caspase-1 (Jin et al., 2013). The roles of these NLRP3 inflammasome regulatory pathways during $\mathrm{Mtb}$ infections have not been investigated.

\section{INTERACTION OF MTB WITH HOST CELL AIM2-INFLAMMASOME}

Intracellular bacterial pathogens such as F. tularensis and L. monocytogenes have been shown to induce the AIM2-inflammasome (Fernandes-Alnemri et al., 2010; Jones et al., 2010; Sauer et al., 2010; Tsuchiya et al., 2010). Interestingly, bacterial mutants of F. tularensis and L. monocytogenes in virulence factors that are important for bacterial access to host cell cytosol are deficient in activation of the inflammasome (Henry et al., 2007; Sauer et al., 2010). It is believed that during access to host cell cytosol some bacterial dsDNA also enters the cytosol where it will be recognized by AIM2 (Fernandes-Alnemri et al., 2010; Jones et al., 2010; Sauer et al., 2010). Indeed, AIM2 binds indiscriminately to cytosolic double-stranded DNA which could be of artificial (poly dA:dT), microbial or mammalian origin (Muruve et al., 2008; Rathinam et al., 2010).
The type VII secretion system (ESX-1) of Mtb mediates translocation of Mtb extracellular DNA (eDNA) into the host cell cytosol where it can activate the DNA sensor IFI16/IFI204 which results in the initiation of a signaling cascade that ultimately leads to the production of IFN- $\beta$ (Figure 1) (Stanley et al., 2007; Manzanillo et al., 2012). In the light of the indiscriminate binding of AIM2 to dsDNA it is surprising that the cytosolic Mtb eDNA does not induce activation of the AIM2 inflammasome. A clue on how to resolve this conundrum was offered by our recent finding that Mtb does not induce AIM2inflammasome activation but other NTM, such as M. smegmatis (Msme), do (Shah et al., 2013). Msme has a functional ESX1 system that is important for conjugal DNA transfer (Flint et al., 2004). Similar to the L. monocytogenes listeriolysin O mutant, the ESX-1 deficient Msme mutant showed a significant reduction in AIM2-inflammasome activation. Furthermore, Mtb could inhibit AIM2-inflammasome activation induced by infection with either Msme or the transfection of dsDNA (Shah et al., 2013). This inhibition by Mtb was dependent upon the presence of a functional ESX-1 system, since an ESX-1 deficient Mtb mutant failed to inhibit AIM2 activation (Shah et al., 2013). This suggests that the same secretion system that is responsible for introducing AIM2 ligands into the host cell cytosol may also transfer an effector that inhibits the AIM2 activation (Figure 1). The ESX-1 secretion system is also important for the escape of a fraction of intracellular Mtb from the phagosome into the cytosol (Van Der Wel et al., 2007; Houben et al., 2012; Simeone et al., 2012). The entry of Mtb into the cytosol

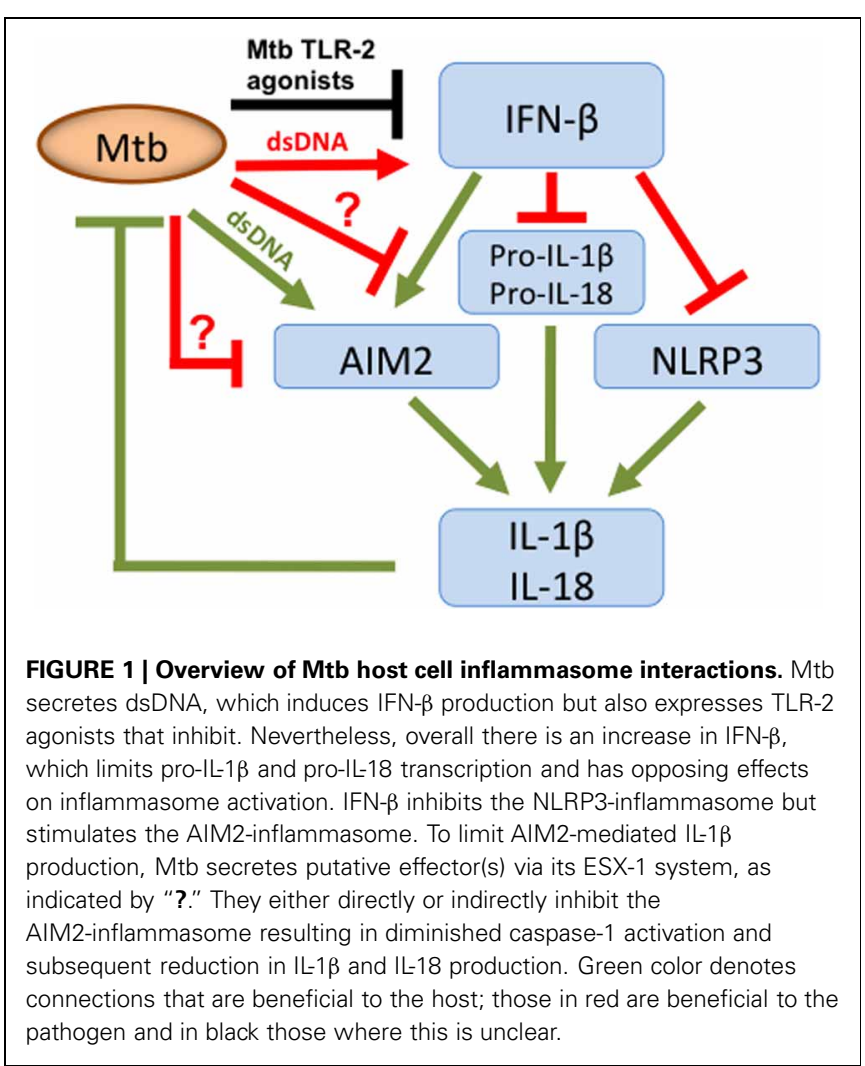


could be another pathway for AIM2-inflammasome activation as it has been described for other bacteria that escape the phagosome (Brodsky and Monack, 2009). Nevertheless, Mtb escapes the phagosome at a very late stage (only after several days) during the infection (Houben et al., 2012; Simeone et al., 2012). In contrast, IL- $1 \beta$ production is usually analyzed within the first $24 \mathrm{~h}$ of infection and hence the current data in the literature on Mtb-inflammasome activation does not take the Mtb entry in the host cell cytosol into account. Analysis of these events during the late phase of the infection cycle would be very informative and may reveal Mtb-mediated AIM2-inflammasome activation.

The importance and probably also the limits of Mtb-mediated AIM2 inflammasome inhibition are highlighted by a study that demonstrates the increased susceptibility of $A \mathrm{im} 2^{-/-}$mice and decreased levels of IL-1 $\beta$ and IL-18 in the lungs of these mice after Mtb infection (Saiga et al., 2012). The ex vivo analysis of macrophage infection in this study, demonstrating reduced IL$1 \beta$ secretion in Aim $2^{-/-}$cells is in contradiction to many reports showing the sole dependence of BMDMs on NLRP3 for IL-1 $\beta$ production after Mtb infection. This may be due to the nature of macrophages used because in Saiga et al. thioglycollate-induced peritoneal macrophages were used as opposed to BMDMs in (Mayer-Barber et al., 2010; Mcelvania Tekippe et al., 2010; Mishra et al., 2010; Wong and Jacobs, 2011; Abdalla et al., 2012; Dorhoi et al., 2012). A more recent report that virulent $M$. bovis induce AIM2-inflammasome activation in a murine macrophage cell line further underscores the potential for AIM2-inflammasome in host defense against mycobacteria (Yang et al., 2013).

\section{THE ROLE OF IFN- $\beta$ IN MTB-INFLAMMASOME INTERACTIONS}

The significance of type I IFN signaling for activation of AIM2-inflammasome responses was first reported for F. tularensis and L. monocytogenes infected macrophages (Henry et al., 2007). Some reports demonstrate that the IFN- $\beta$ acts at the level of increased transcription and translation of Aim2 in order to increase AIM2-inflammasome activity (Jones et al., 2010; Tsuchiya et al., 2010). A conflicting report failed to detect changes in protein levels of AIM2 after infection with F. tularensis but confirmed the importance of this cytokine for AIM2-inflammasome activation (Fernandes-Alnemri et al., 2010). We reported that NTM induce secretion of up to 20fold higher levels of IFN- $\beta$ when compared to Mtb infection (Shah et al., 2013). Furthermore, experiments using IFN- $\beta$ neutralizing antibodies and Ifnar1 $1^{-/-}$ deficient cells demonstrated a stimulatory role of IFN- $\beta$ in the context of infections with NTMs (Shah et al., 2013). This is very comparable to the effect of IFN- $\beta$ during F. tularensis or L. monocytogenes mediated inflammasome activation (Henry et al., 2007; Tsuchiya et al., 2010). Consequently, one could argue that minimizing IFN- $\beta$ production will optimize the virulence of $\mathrm{Mtb}$ since there was an inverse correlation between IFN- $\beta$ production and virulence. Nevertheless, the current paradigm is that an increase in type I IFN production leads to increased Mtb virulence (Manca et al., 2001, 2005; Stanley et al., 2007; Berry et al., 2010; Mayer-Barber et al., 2011; Manzanillo et al., 2012).
During the course of Mtb ex vivo infections of macrophages and dendritic cells no AIM2-inflammasome activation is detected. In this context, IFN- $\beta$ has the opposite effect and suppresses activation of the NLRP3 inflammasome (Figure 1) (Mayer-Barber et al., 2011; Novikov et al., 2011). The mechanism of this inhibition involves the IFN- $\beta$ mediated induction of IL-10 which suppresses IL- $1 \beta$ production (Mayer-Barber et al., 2011; Novikov et al., 2011). How then does Mtb inhibit the AIM2inflammasome in the presence of IFN- $\beta$ ? The pre-infection of cells with Mtb inhibited IFN- $\beta$ production induced by Msme in an ESX-1 dependent manner (Shah et al., 2013). This is in agreement with a previous report demonstrating that Mtbinduced TLR-2 signaling leads to depletion of IRAK1, which is required for TLR7/9-induced IFN- $\beta$ production (Liu et al., 2012). These two reports show that $\mathrm{Mtb}$ is able to inhibit the production of IFN- $\beta$ (Liu et al., 2012; Shah et al., 2013). Nevertheless, we demonstrated that the inhibition of IFN- $\beta$ production is only a minor cause of the Mtb-mediated AIM2-inflammasome inhibition, since adding extracellular IFN- $\beta$ did not completely overcome the inhibition (Shah et al., 2013). In addition, we showed that $\mathrm{Mtb}$ is capable of inhibiting autocrine IFN- $\beta$ signaling (Shah et al., 2013). This observation is consistent with the previous report that Mtb inhibits IFN- $\alpha$ signaling, by reducing STAT1 phosphorylation and homodimer formation, since IFN- $\beta$ and IFN- $\alpha$ signal through the same receptor (Prabhakar et al., 2003). This inhibition of IFN- $\beta$ signaling may be linked to the inhibition of the AIM2 inflammasome but via a pathway that does not involve transcription or translational regulation of Aim2, since those were not affected by Mtb infection (Shah et al., 2013). Clearly, further investigation is needed to determine the molecular mechanism of Mtb mediated AIM2inflammasome inhibition and its importance for bacterial virulence. In addition, the inhibition of IFN- $\beta$ signaling could have the added benefit of reducing the production of IL- $1 \beta$ via the NLRP3 inflammasome. One example of a mechanism for such an inhibition could be the effect on caspase-11 activation, which is part of the IFNAR1 signaling pathway engaged by IFN- $\beta$. The activated caspase- 11 synergizes with caspase- 1 during NLRP3-inflammasome mediated maturation of pro-IL-1 $\beta$ (Rathinam et al., 2012). In conclusion, Mtb may have adapted to exploiting the pathogen-beneficial functions of IFN- $\beta$ to exacerbate disease and inhibit the NLRP3-inflammasome by inhibiting potentially detrimental effects of IFN- $\beta$, which are the activation of the AIM2-inflammasome and autocrine IFN- $\beta$ signaling (Figure 1).

Another point accentuated by our study (Shah et al., 2013) is that approaches comparing virulent $\mathrm{Mtb}$ with a broader spectrum of NTMs may help pointing toward inhibitory capacities of $\mathrm{Mtb}$ as it has done for the interaction of Mtb with host cell death (Keane et al., 2000; Velmurugan et al., 2007) and for host cell autophagy (Shin et al., 2010; Zullo and Lee, 2012). The long co-evolution of Mtb with humans and the selective pressure applied to human host defense to recognize and react to Mtb infections leads to the induction of innate immune responses. Nevertheless, Mtb, having been exposed to these responses, has adapted to counteract them, which is not the case for NTM. Consequently, comparing host responses quantitatively between 
virulent Mtb and NTM may offer clues to other Mtb-specific inhibitory mechanisms.

\section{BACTERIAL MEDIATORS OF INFLAMMASOME INHIBITION}

The inhibition of host cell inflammasome response as an immune evasion strategy has been described for viruses and bacterial pathogens (Taxman et al., 2010; Lamkanfi and Dixit, 2011; Vande Walle and Lamkanfi, 2011; Higa et al., 2013). The Pseudomonas aeruginosa secreted effectors ExoU and ExoS both mediate suppression of NLRC4-inflammasome dependent IL- $1 \beta$ production via unknown mechanisms (Sutterwala et al., 2007; Galle et al., 2008). The Yersinia enterocolitica proteins YopE and YopT both inhibit caspase-1 activation by targeting host cell Racl protein (Schotte et al., 2004). The Y. pseudotuberculosis YopK proteins bind to components of the bacterial type III secretion system to inhibit their recognition by host cell inflammasome (Brodsky et al., 2010). Legionella interferes with inflammasome activation by inhibiting transcription of the important inflammasome adapter gene ASC (Abdelaziz et al., 2011).

The Zn-metalloprotease, ZMP1, of Mtb has been implicated in inhibiting activation of the NLRP3-inflammasome (Master et al., 2008). Nevertheless, an independently generated zmp1 Mtb deletion mutant failed to reproduce this phenotype (Wong and Jacobs, 2011). One reason for this difference may be that most experiments in the study by Master et al. were performed using a zmp1 mutant in the background of the vaccine strain M. bovis BCG which lacks functional ESX-1 system. Another difference between the studies was the type of host cell being murine cells vs. human THP-1 cell line. The Mtb Rv3364c protein can bind to and inhibit host cell protease, cathepsin G (Danelishvili et al., 2011). This inhibition leads to a reduction in caspase-1 activity and pyroptosis of host cells (Danelishvili et al., 2011). The impact of the inhibition of caspase-1 on IL$1 \beta$ production has not been addressed in that study. Cathepsin $\mathrm{G}$ has also been implicated in inflammasome independent processing of pro-IL-1 $\beta$ to mature IL-1 $\beta$ (Hazuda et al., 1990). Hence there are two potential pathways for the Rv3364c proteins to limit IL-1 $\beta$ production after Mtb infection. Our recent results suggest that an ESX-1-dependent secreted effector of Mtb is mediating the inhibition of host cell AIM2-inflammasome (Shah et al., 2013). In addition, other Mtb proteins may limit the NLRP3-inflammasome activation via inhibition of IFN- $\beta$ signaling (Rathinam et al., 2012). In conclusion, there is a growing list of important human bacterial pathogens that have developed

\section{REFERENCES}

Abdalla, H., Srinivasan, L., Shah, S., Mayer-Barber, K. D., Sher, A., Sutterwala, F. S., et al. (2012). Mycobacterium tuberculosis infection of dendritic cells leads to partially caspase-1/11-independent IL-1ß and IL-18 secretion but not to pyroptosis. PLoS ONE 7:e40722. doi: 10.1371/journal. pone. 0040722

Abdelaziz, D. H., Gavrilin, M. A., Akhter, A., Caution, K., Kotrange, S., Khweek, A. A., et al. (2011).
Apoptosis-associated speck-like protein (ASC) controls Legionella pneumophila infection in human monocytes. J. Biol. Chem. 286, 3203-3208. doi: 10.1074/jbc.M110. 197681

Berry, M. P., Graham, C. M., Mcnab, F. W., Xu, Z., Bloch, S. A., Oni, T., et al. (2010). An interferoninducible neutrophil-driven blood transcriptional signature in human tuberculosis. Nature 466, 973-977. doi: 10.1038/nature 09247 strategies to manipulate the host cell inflammasome, hence lending indirectly support to the argument that IL- $1 \beta$ production is important to host defense. The molecular mechanisms and especially the bacterial effectors involved in Mtb's interaction with host cell inflammasome are poorly defined and merit further investigations.

\section{CONCLUSIONS}

The importance of IL-1 $\beta$ for host immune defense against Mtb infections is established (Mayer-Barber et al., 2010; Mcelvania Tekippe et al., 2010; Mayer-Barber et al., 2011). It is also clear that in vivo IL-1 $\beta$ levels are not affected by the absence of NLRP3 or ASC during Mtb infections, which highlights the importance of inflammasome-independent pathways (MayerBarber et al., 2010; Mcelvania Tekippe et al., 2010; Walter et al., 2010). Consistently, $\mathrm{Nlrp}^{-/-}$mice are not more susceptible and $\mathrm{Asc}^{-/-}$mice are only slightly more susceptible to Mtb infections (Mayer-Barber et al., 2010; Mcelvania Tekippe et al., 2010; Dorhoi et al., 2012). Here we discussed recent reports demonstrating that Mtb can inhibit NLRP3-inflammasome activity via an IFN- $\beta$ pathway and also either directly or indirectly inhibits the AIM2-inflammasome. In the light of these findings it is compelling to hypothesize that Mtb may actually be proficient at inhibiting other types of inflammasomes. Following this line of thought it may be that the $\mathrm{Nlrp}^{-/-}$and $\mathrm{Asc}^{-/-}$mice have none to only minor phenotypes respectively, because Mtb is already so efficient at inhibiting their activity that even completely taking away these components of the host defense does not make much of a difference. Instead, host immune defense has evolved to develop inflammasome-independent pathways for IL- $1 \beta$ production to combat the highly adapted human pathogen Mtb. Serine proteases such as proteinase- 3 , elastase and cathepsin- $G$ of neutrophils have been described to mature pro-IL-1 $\beta$ independently of inflammasome activation (Netea et al., 2010). It will be interesting to investigate if any of the two major cell populations responsible for IL- $1 \beta$ production in the lungs during $\mathrm{Mtb}$ infection use this mechanism to mature pro-IL-1 $\beta$ (Mayer-Barber et al., 2011).

\section{ACKNOWLEDGMENTS}

We would like to thank Drs. K. Mayer-Barber (NIH) and F. Sutterwala (University of Iowa) for critical reading and helpful comments. Research in the Briken lab is supported by NIH Grant AI072584.
Host Microbe. 7, 376-387. doi: 10.1016/j.chom.2010.04.009

Burckstummer, T., Baumann, C., Bluml, S., Dixit, E., Durnberger, G., Jahn, H., et al. (2009). An orthogonal proteomic-genomic screen identifies AIM2 as a cytoplasmic DNA sensor for the inflammasome. Nat. Immunol. 10, 266-272. doi: 10.1038/ni.1702

Carlsson, F., Kim, J., Dumitru, C., Barck, K. H., Carano, R. A., Sun, M., et al. (2010). Host-detrimental role of Esx-1-mediated inflammasome 
activation in mycobacterial infection. PLoS Pathog 6:e1000895. doi: 10.1371/journal. ppat. 1000895

Chen, C. C., Tsai, S. H., Lu, C. C., Hu, S. T., Wu, T. S., Huang, T. T., et al. (2012). Activation of an NLRP3 inflammasome restricts Mycobacterium kansasii infection. PLoS ONE 7:e36292. doi: 10.1371/journal.pone.0036292

Cooper, A. M., Mayer-Barber, K. D., and Sher, A. (2011). Role of innate cytokines in mycobacterial infection. Mucosal Immunol. 4, 252-260. doi: $10.1038 / \mathrm{mi} .2011 .13$

Danelishvili, L., Everman, J. L., Mcnamara, M. J., and Bermudez, L. E. (2011). Inhibition of the PlasmaMembrane-Associated Serine Protease Cathepsin G by Mycobacterium tuberculosis Rv3364c Suppresses Caspase-1 and Pyroptosis in Macrophages. Front. Microbiol. 2:281. doi: 10.3389/fmicb.2011.00281

Dorhoi, A., Nouailles, G., Jorg, S., Hagens, K., Heinemann, E., Pradl, L., et al. (2012). Activation of the NLRP3 inflammasome by Mycobacterium tuberculosis is uncoupled from susceptibility to active tuberculosis. Eur. J. Immunol. 42, 374-384. doi: 10.1002/eji.201141548

Fernandes-Alnemri, T., Yu, J. W., Datta, P., Wu, J., and Alnemri, E. S. (2009). AIM2 activates the inflammasome and cell death in response to cytoplasmic DNA. Nature 458, 509-513. doi: 10.1038/nature07710

Fernandes-Alnemri, T., Yu, J. W., Juliana, C., Solorzano, L., Kang, S., Wu, J., et al. (2010). The AIM2 inflammasome is critical for innate immunity to Francisella tularensis. Nat. Immunol. 11, 385-393. doi: 10.1038/ni. 1859

Flint, J. L., Kowalski, J. C., Karnati, P. K., and Derbyshire, K. M. (2004). The RD1 virulence locus of Mycobacterium tuberculosis regulates DNA transfer in Mycobacterium smegmatis. Proc. Natl. Acad. Sci. U.S.A. 101, 12598-12603. doi: 10.1073/pnas.0404892101

Galle, M., Schotte, P., Haegman, M., Wullaert, A., Yang, H. J., Jin, S., et al. (2008). The Pseudomonas aeruginosa type III secretion system plays a dual role in the regulation of caspase-1 mediated IL1beta maturation. J. Cell. Mol. Med. 12, 1767-1776. doi: 10.1111/j.15824934.2007.00190.x

Gringhuis, S. I., Kaptein, T. M., Wevers, B. A., Theelen, B., Van Der Vlist, M., Boekhout, T., et al.
(2012). Dectin-1 is an extracellular pathogen sensor for the induction and processing of IL-1beta via a noncanonical caspase-8 inflammasome. Nat. Immunol. 13, 246-254. doi: $10.1038 /$ ni.2222

Gross, O., Poeck, H., Bscheider, M., Dostert, C., Hannesschlager, N., Endres, S., et al. (2009). Syk kinase signalling couples to the Nlrp3 inflammasome for anti-fungal host defence. Nature 459, 433-436. doi: 10.1038/nature07965

Hazuda, D. J., Strickler, J., Kueppers, F., Simon, P. L., and Young, P. R. (1990). Processing of precursor interleukin 1 beta and inflammatory disease. J. Biol. Chem. 265, 6318-6322.

Henry, T., Brotcke, A., Weiss, D. S., Thompson, L. J., and Monack, D. M. (2007). Type I interferon signaling is required for activation of the inflammasome during Francisella infection. J. Exp. Med. 204, 987-994. doi: $10.1084 /$ jem. 20062665

Hernandez-Cuellar, E., Tsuchiya, K., Hara, H., Fang, R., Sakai, S., Kawamura, I., et al. (2012). Cutting edge: nitric oxide inhibits the NLRP3 inflammasome. J. Immunol. 189, 5113-5117. doi: 10.4049/jimmunol.1202479

Higa, N., Toma, C., Nohara, T., Nakasone, N., Takaesu, G., and Suzuki, T. (2013). Lose the battle to win the war: bacterial strategies for evading host inflammasome activation. Trends Microbiol. 21, 342-349. doi: 10.1016/j.tim.2013.04.005

Hornung, V., Ablasser, A., CharrelDennis, M., Bauernfeind, F., Horvath, G., Caffrey, D. R., et al. (2009). AIM2 recognizes cytosolic dsDNA and forms a caspase-1activating inflammasome with ASC. Nature 458, 514-518. doi: 10.1038/nature 07725

Houben, D., Demangel, C., Van Ingen, J., Perez, J., Baldeon, L., Abdallah, A. M., et al. (2012). ESX-1-mediated translocation to the cytosol controls virulence of mycobacteria. Cell. Microbiol. 14, 1287-1298. doi: 10.1111/j.1462-5822.2012.01799.x

Iyer, S. S., He, Q., Janczy, J. R., Elliott, E. I., Zhong, Z., Olivier, A. K., et al. (2013). Mitochondrial cardiolipin is required for Nlrp3 inflammasome activation. Immunity 39, 311-323. doi: 10.1016/j.immuni.2013.08.001

Jin, J., Yu, Q., Han, C., Hu, X., Xu, S., Wang, Q., et al. (2013). LRRFIP2 negatively regulates NLRP3 inflammasome activation in macrophages by promoting Flightless-I-mediated caspase-1 inhibition. Nat. Commun. 4, 2075. doi: $10.1038 /$ ncomms 3075
Jones, J. W., Kayagaki, N., Broz, P., Henry, T., Newton, K., O'rourke, K., et al. (2010). Absent in melanoma 2 is required for innate immune recognition of Francisella tularensis. Proc. Natl. Acad. Sci. U.S.A. 107, 9771-9776. doi: $10.1073 /$ pnas. 1003738107

Keane, J., Remold, H. G., and Kornfeld, H. (2000). Virulent Mycobacterium tuberculosis strains evade apoptosis of infected alveolar macrophages. J. Immunol. 164, 2016-2020.

Kurenuma, T., Kawamura, I., Hara, H., Uchiyama, R., Daim, S., Dewamitta, S. R., et al. (2009). The RD1 locus in the Mycobacterium tuberculosis genome contributes to activation of caspase-1 via induction of potassium ion efflux in infected macrophages. Infect. Immun. 77, 3992-4001. doi: 10.1128/IAI 00015-09

Lamkanfi, M., and Dixit, V. M. (2011). Modulation of inflammasome pathways by bacterial and viral pathogens. J. Immunol. 187, 597-602. doi 10.4049/jimmunol.1100229

Lee, H. M., Kang, J., Lee, S. J., and Jo, E. K. (2013). Microglial activation of the NLRP3 inflammasome by the priming signals derived from macrophages infected with mycobacteria. Glia 61, 441-452. doi: 10.1002/glia.22448

Lee, H. M., Yuk, J. M., Kim, K. H., Jang, J., Kang, G., Park, J. B., et al. (2012). Mycobacterium abscessus activates the NLRP3 inflammasome via Dectin-1-Syk and p62/SQSTM1. Immunol. Cell Biol. 90, 601-610. doi: 10.1038/icb.2011.72

Liu, Y. C., Simmons, D. P., Li, X., Abbott, D. W., Boom, W. H., and Harding, C. V. (2012). TLR2 signaling depletes IRAK1 and inhibits induction of type I IFN by TLR7/9. J. Immunol. 188, 1019-1026. doi: 10.4049/jimmunol.1102181

Manca, C., Tsenova, L., Bergtold, A., Freeman, S., Tovey, M., Musser, J. M., et al. (2001). Virulence of a Mycobacterium tuberculosis clinical isolate in mice is determined by failure to induce Thl type immunity and is associated with induction of IFN-alpha /beta. Proc. Natl. Acad. Sci. U.S.A. 98, 5752-5757. doi: 10.1073/pnas.091096998

Manca, C., Tsenova, L., Freeman, S., Barczak, A. K., Tovey, M., Murray, P. J., et al. (2005). Hypervirulent M. tuberculosis W/Beijing strains upregulate type I IFNs and increase expression of negative regulators of the Jak-Stat pathway. J. Interferon Cytokine Res. 25, 694-701. doi: 10.1089/jir.2005.25.694
Manzanillo, P. S., Shiloh, M. U., Portnoy, D. A., and Cox, J. S. (2012). Mycobacterium tuberculosis activates the DNA-dependent cytosolic surveillance pathway within macrophages. Cell Host Microbe. 11, 469-480. doi: 10.1016/j.chom.2012.03.007

Master, S. S., Rampini, S. K., Davis, A. S., Keller, C., Ehlers, S., Springer, B., et al. (2008). Mycobacterium tuberculosis prevents inflammasome activation. Cell Host Microbe. 3, 224-232. doi: 10.1016/j.chom.2008.03.003

Mayer-Barber, K. D., Andrade, B. B., Barber, D. L., Hieny, S., Feng, C. G., Caspar, P., et al. (2011). Innate and adaptive interferons suppress ILlalpha and IL-1beta production by distinct pulmonary myeloid subsets during Mycobacterium tuberculosis infection. Immunity 35, 1023-1034. doi: 10.1016/j.immuni.2011.12.002

Mayer-Barber, K. D., Barber, D. L., Shenderov, K., White, S. D., Wilson, M. S., Cheever, A., et al. (2010). Caspase-1 independent IL-1beta production is critical for host resistance to Mycobacterium tuberculosis and does not require TLR signaling in vivo. J. Immunol. 184, 3326-3330. doi: 10.4049/jimmunol.0904189

Mcelvania Tekippe, E., Allen, I. C., Hulseberg, P. D., Sullivan, J. T., Mccann, J. R., Sandor, M., et al. (2010). Granuloma formation and host defense in chronic Mycobacterium tuberculosis infection requires PYCARD/ASC but not NLRP3 or caspase1. PLoS ONE 5:e12320. doi: 10.1371/journal.pone. 0012320

Mishra, B. B., Moura-Alves, P., Sonawane, A., Hacohen, N., Griffiths, G., Moita, L. F., et al. (2010). Mycobacterium tuberculosis protein ESAT-6 is a potent activator of the NLRP3/ASC inflammasome. Cell. Microbiol. 12, 1046-1063. doi: 10.1111/j.1462-5822.2010.01450.x

Mishra, B. B., Rathinam, V. A., Martens, G. W., Martinot, A. J., Kornfeld, H., Fitzgerald, K. A., et al. (2013). Nitric oxide controls the immunopathology of tuberculosis by inhibiting NLRP3 inflammasome-dependent processing of IL-1beta. Nat. Immunol. 14, 52-60. doi: 10.1038/ni.2474

Mitoma, H., Hanabuchi, S., Kim, T., Bao, M., Zhang, Z., Sugimoto, N., et al. (2013). The DHX33 RNA helicase senses cytosolic RNA and activates the NLRP3 inflammasome. Immunity 39, 123-135. doi: 10.1016/j.immuni.2013.07.001

Munoz-Planillo, R., Kuffa, P., MartinezColon, G., Smith, B. L., Rajendiran, 
T. M., and Nunez, G. (2013). K(+) efflux is the common trigger of NLRP3 inflammasome activation by bacterial toxins and particulate matter. Immunity 38, 1142-1153. doi: 10.1016/j.immuni.2013.05.016

Muruve, D. A., Petrilli, V., Zaiss, A. K., White, L. R., Clark, S. A., Ross, P. J., et al. (2008). The inflammasome recognizes cytosolic microbial and host DNA and triggers an innate immune response. Nature 452, 103-107. doi: 10.1038/nature06664

Netea, M. G., Simon, A., Van De Veerdonk, F., Kullberg, B. J., Van Der Meer, J. W., and Joosten, L. A. (2010). IL-1beta processing in host defense: beyond the inflammasomes. PLoS Pathog. 6:e1000661. doi: 10.1371/journal.ppat.1000661

Novikov, A., Cardone, M., Thompson, R., Shenderov, K., Kirschman, K. D., Mayer-Barber, K. D., et al. (2011). Mycobacterium tuberculosis triggers host type I IFN signaling to regulate IL-1beta production in human macrophages. J. Immunol. 187, 2540-2547. doi: 10.4049/jimmunol.1100926

Prabhakar, S., Qiao, Y., Hoshino, Y., Weiden, M., Canova, A., Giacomini, E., et al. (2003). Inhibition of response to alpha interferon by Mycobacterium tuberculosis. Infect. Immun. 71, 2487-2497. doi: 10.1128/IAI.71.5.2487-2497.2003

Rathinam, V. A., Jiang, Z., Waggoner, S. N., Sharma, S., Cole, L. E., Waggoner, L., et al. (2010). The AIM2 inflammasome is essential for host defense against cytosolic bacteria and DNA viruses. Nat. Immunol. 11, 395-402. doi: 10.1038/ni.1864

Rathinam, V. A., Vanaja, S. K., Waggoner, L., Sokolovska, A., Becker, C., Stuart, L. M., et al. (2012). TRIF licenses caspase-11dependent NLRP3 inflammasome activation by gram-negative bacteria. Cell 150, 606-619. doi: 10.1016/j.cell.2012.07.007

Saiga, H., Kitada, S., Shimada, Y., Kamiyama, N., Okuyama, M., Makino, M., et al. (2012). Critical role of AIM2 in Mycobacterium tuberculosis infection. Int. Immunol. 24, 637-644. doi: 10.1093/intimm/dxs062

Sauer, J. D., Witte, C. E., Zemansky, J., Hanson, B., Lauer, P., and Portnoy,
D. A. (2010). Listeria monocytogenes triggers AIM2-mediated pyroptosis upon infrequent bacteriolysis in the macrophage cytosol. Cell Host Microbe. 7, 412-419. doi: 10.1016/j.chom.2010.04.004

Schotte, P., Denecker, G., Van Den Broeke, A., Vandenabeele, P., Cornelis, G. R., and Beyaert, R. (2004). Targeting Racl by the Yersinia effector protein YopE inhibits caspase-1-mediated maturation and release of interleukin-1beta. J. Biol. Chem. 279, 25134-25142. doi: 10.1074/jbc.M401245200

Schroder, K., and Tschopp, J. (2010). The inflammasomes. Cell 140, 821-832. doi: 10.1016/j.cell.2010.01.040

Shah, S., Bohsali, A., Ahlbrand, S. E., Srinivasan, L., Rathinam, V.A.K., Vogel, S. N., et al. (2013). Cutting edge: Mycobacterium tuberculosis but not nonvirulent mycobacteria inhibits IFN- $\beta$ and AIM2 inflammasome-dependent IL-1 $\beta$ production via its ESX-1 secretion system. J. Immunol. 191, 3514-3518. doi: 10.4049/jimmunol. 1301331

Shenoy, A. R., Wellington, D. A., Kumar, P., Kassa, H., Booth, C. J., Cresswell, P., et al. (2012). GBP5 promotes NLRP3 inflammasome assembly and immunity in mammals. Science 336, 481-485. doi: 10.1126/science.1217141

Shin, D. M., Jeon, B. Y., Lee, H. M., Jin, H. S., Yuk, J. M., Song, C. H., et al. (2010). Mycobacterium tuberculosis eis regulates autophagy, inflammation, and cell death through redox-dependent signaling. PLoS Pathog. 6:e1001230. doi: 10.1371/journal.ppat.1001230

Simeone, R., Bobard, A., Lippmann, J., Bitter, W., Majlessi, L., Brosch, R., et al. (2012). Phagosomal rupture by Mycobacterium tuberculosis results in toxicity and host cell death. PLoS Pathog. 8:e1002507. doi: 10.1371/journal.ppat.1002507

Stanley, S. A., Johndrow, J. E., Manzanillo, P., and Cox, J. S. (2007). The type I IFN response to infection with Mycobacterium tuberculosis requires ESX-1-mediated secretion and contributes to pathogenesis. J. Immunol. 178, 3143-3152.
Sutterwala, F. S., Mijares, L. A., Li, L., Ogura, Y., Kazmierczak, B. I., and Flavell, R. A. (2007). Immune recognition of Pseudomonas aeruginosa mediated by the IPAF/NLRC4 inflammasome. J. Exp. Med. 204, 3235-3245. doi: 10.1084/jem.20071239

Taxman, D. J., Huang, M. T., and Ting, J. P. (2010). Inflammasome inhibition as a pathogenic stealth mechanism. Cell Host Microbe. 8, 7-11. doi: 10.1016/j.chom.2010. 06.005

Tsuchiya, K., Hara, H., Kawamura, I., Nomura, T., Yamamoto, T., Daim, S., et al. (2010). Involvement of absent in melanoma 2 in inflammasome activation in macrophages infected with Listeria monocytogenes. J. Immunol. 185, 1186-1195. doi: 10.4049/jimmunol.1001058

Van Der Wel, N., Hava, D., Houben, D., Fluitsma, D., Van Zon, M., Pierson, J., et al. (2007). M. tuberculosis and $M$. leprae translocate from the phagolysosome to the cytosol in myeloid cells. Cell 129, 1287-1298. doi: 10.1016/j.cell.2007.05.059

Vande Walle, L., and Lamkanfi, M. (2011). Inflammasomes: caspase1-activating platforms with critical roles in host defense. Front. Microbiol. 2:3. doi: 10.3389/fmicb. 2011.00003

Velmurugan, K., Chen, B., Miller, J. L., Azogue, S., Gurses, S., Hsu, T., et al. (2007). Mycobacterium tuberculosis nuoG is a virulence gene that inhibits apoptosis of infected host cells. PLOS Pathog. 3:e110. doi: 10.1371/journal.ppat.0030110

Walter, K., Holscher, C., Tschopp, J., and Ehlers, S. (2010). NALP3 is not necessary for early protection against experimental tuberculosis. Immunobiology 215, 804-811. doi: 10.1016/j.imbio.2010.05.015

Wong, K. W., and Jacobs, W. R. Jr. (2011). Critical role for NLRP3 in necrotic death triggered by Mycobacterium tuberculosis. Cell. Microbiol. 13, 1371-1384. doi: 10.1111/j.1462-5822.2011.01625.x

Yan, Y., Jiang, W., Spinetti, T., Tardivel, A., Castillo, R., Bourquin, C., et al. (2013). Omega-3 fatty acids prevent inflammation and metabolic disorder through inhibition of NLRP3 inflammasome activation.
Immunity 38, 1154-1163. doi: 10.1016/j.immuni.2013.05.015

Yang, Y., Zhou, X., Kouadir, M., Shi, F., Ding, T., Liu, C., et al. (2013). The AIM2 inflammasome is involved in macrophage activation during infection with virulent Mycobacterium bovis strain. J. Infect. Dis. doi: 10.1093/infdis/jit347. [Epub ahead of print].

Zhou, R., Tardivel, A., Thorens, B., Choi, I., and Tschopp, J. (2010). Thioredoxin-interacting protein links oxidative stress to inflammasome activation. Nat. Immunol. 11, 136-140. doi: 10.1038/ ni.1831

Zullo, A. J., and Lee, S. (2012). Mycobacterial induction of autophagy varies by species and occurs independently of mammalian target of rapamycin inhibition. J. Biol. Chem. 287, 12668-12678. doi: 10.1074/jbc. M111.320135

Conflict of Interest Statement: The authors declare that the research was conducted in the absence of any commercial or financial relationships that could be construed as a potential conflict of interest.

Received: 02 September 2013; paper pending published: 12 September 2013; accepted: 23 September 2013; published online: 09 October 2013.

Citation: Briken V, Ahlbrand SE and Shah $S$ (2013) Mycobacterium tuberculosis and the host cell inflammasome: a complex relationship. Front. Cell. Infect. Microbiol. 3:62. doi: 10.3389/ fcimb.2013.00062

This article was submitted to the journal Frontiers in Cellular and Infection Microbiology.

Copyright (c) 2013 Briken, Ahlbrand and Shah. This is an open-access article distributed under the terms of the Creative Commons Attribution License (CC BY). The use, distribution or reproduction in other forums is permitted, provided the original author(s) or licensor are credited and that the original publication in this journal is cited, in accordance with accepted academic practice. No use, distribution or reproduction is permitted which does not comply with these terms. 